\title{
Aktivitas Antibakteri Fraksi Ekstrak Etanol Daun Trembesi (Samanea saman (Jacq.) Merr) terhadap Staphylococcus aureus
}

\author{
Ni Ketut Sinarsih ${ }^{1 *}$, Wiwik Susanah Rita ${ }^{2}$, Ni Made Puspawati ${ }^{3}$ \\ ${ }^{1}$ Universitas Hindu Negeri I Gusti Bagus Sugriwa, Denpasar, Indonesia \\ 2,3 Universitas Udayana, Denpasar, Indonesia \\ *e-mail: nktsinarsih@gmail.com
}

\begin{abstract}
Abstrak
Penelitian ini dilakukan untuk menentukan aktivitas antibakteri fraksi-fraksi dari partisi ekstrak etanol daun trembesi dalam menghambat pertumbuhan bakteri $S$. aureus, yang meliputi ekstraksi daun trembesi dengan pelarut etanol, partisi menggunakan pelarut $n$-heksan, etil asetat, dan n-butanol, penentuan daya hambat fraksi hasil partisi, serta penentuan Konsentrasi Hambat Minimum (KHM) dari fraksi yang menunjukkan aktivitas penghambatan terbaik untuk menghambat pertumbuhan S. Aureus. Hasil penelitian menunjukkan bahwa dari $2000 \mathrm{~g}$ sampel diperoleh ekstrak kental sebanyak $160 \mathrm{~g}$. Proses partisi menghasilkan empat fraksi yaitu fraksi $\mathrm{n}$-heksan yang berwarna hijau tua, fraksi etil-asetat yang berwarna hijau kecoklatan, fraksi nbutanol yang berwarna coklat tua, dan fraksi air yang berwarna coklat pekat. Dari keempat fraksi, hanya fraksi $n$-butanol yang memberikan efek penghambatan terhadap $S$. aureus secara in vitro pada media Mueller Hinton, yaitu sebesar $19,3 \mathrm{~mm}$ pada konsentrasi $15 \%$. Pada konsentrasi tersebut, aktivitas antibakteri fraksi n-butanol dapat dikategorikan kuat terhadap $S$. aureus. Pengujian KHM dilakukan pada tiga konsentrasi yaitu 0,$5 ; 1$; dan $1,5 \%$ dengan diameter hambat aktivitas antibakteri secara berturut -turut sebesar $0 \mathrm{~mm} ; 7,3 \mathrm{~mm}$; dan 9,2 $\mathrm{mm}$.
\end{abstract}

Kata kunci: Samanea saman, antibakteri, partisi, S. aureus

\section{Pendahuluan}

Salah satu masalah kesehatan yang sangat umum diderita oleh masyarakat adalah infeksi. Infeksi adalah penyakit yang disebabkan oleh adanya mikroorganisme yang bersifat patogen yang menginvasi dan berproliferasi dalam jaringan tubuh (Kusuma, 2010). Salah satu jenis mikroorganisme yang dapat menyebabkan infeksi adalah bakteri spesies Staphylococcus aureus ( $S$. aureus). S. aureus dapat menimbulkan penyakit infeksi seperti bisul, jerawat, impetigo, dan infeksi berat seperti pneumonia, mastitis, plebitis, meningitis, infeksi saluran kemih, osteomielitis, dan endokarditis. S. aureus juga merupakan penyebab utama infeksi nosokomial, keracunan makanan, dan sindroma syok toksik (Jawetz et al., 1995).

Kumala et al. (2007) melaporkan bahwa bakteri $S$. aureus resisten terhadap antibiotik meticillin. Peningkatan resistensi bakteri terhadap antibiotik memberikan peluang besar untuk memanfaatkan senyawa bioaktif dari kekayaan keanekaragaman hayati, salah satunya trembesi (Samanea saman (Jacq.) Merr). Potensi trembesi sebagai antibakteri sebelumnya telah dilakukan oleh Sinarsih, dkk (2016), dimana ekstrak etanol daun trembesi menunjukkan aktivitas antibakteri lebih baik dibandingkan ekstrak air terhadap $S$. aureus dan $E$. coli. Sementara itu beberapa penelitian melaporkan bahwa senyawa flavonoid mempunyai berbagai aktivitas, salah satunya sebagai antibakteri. Penelitian mengenai aktivitas flavonoid telah dilakukan oleh Parubak (2013), dimana flavonoid dalam daun akway (Drimys beccariana) mempunyai aktivitas antibakteri terhadap E. coli dan B. subtilis. Berdasarkan fakta-fakta hasil penelitian tersebut maka perlu dilakukan penelitian pendahuluan mengenai aktivitas antibakteri fraksi hasil partisi ekstrak etanol daun trembesi terhadap bakteri $S$. aureus serta menentukan konsentrasi hambat minimum dari fraksi dengan aktivitas terbaik.

\section{Metode}

Penelitian ini menggunakan rancangan deskriptif eksploratif dan eksperimental. Penelitian deskriptif eksploratif yaitu ekstraksi dan isolasi. Penelitian eksperimental meliputi dua tahapan yaitu Tahap (i) uji aktivitas antibakteri untuk penentuan fraksi hasil partisi terbaik dan (ii) konsentrasi hambat minimum (KHM). 


\section{Bahan dan Peralatan}

Bahan-bahan yang digunakan dalam penelitian ini adalah daun trembesi segar yang telah dikeringanginkan dan dihancurkan menjadi serbuk, etanol, akuades, kloroform, $\mathrm{NaOH}$, $\mathrm{H}_{2} \mathrm{SO}_{4}$, pereaksi Meyer, asam asetat anhidrat, nutrient agar, amoxicillin, kertas cakram, mikroorganisme (bakteri $S$. aureus). Alat-alat yang digunakan dalam penelitian ini adalah cawan petri untuk pengujian antibakteri, pinset, labu Erlenmeyer, micropipette, gelas ukur, gelas kimia, blender, rotary evaporator, kain kasa, aluminium foil, kertas saring, kapas, neraca analitik, tabung reaksi, pipet tetes, labu volumetri, cawan petri, autoklaf, mistar.

\section{Ekstraksi daun trembesi}

Ekstraksi daun trembesi dilakukan dengan menggunakan pelarut etanol. Daun trembesi yang telah dikeringanginkan sebanyak $2000 \mathrm{~g}$ digiling hingga membentuk serbuk. Serbuk masing-masing sebanyak $250 \mathrm{~g}$ dimasukkan ke dalam delapan toples untuk diekstraksi menggunakan etanol $96 \%$. Ekstraksi dilakukan dengan merendam serbuk sampel dengan etanol, diaduk hingga homogen dan didiamkan 24 jam. Campuran disaring dan diuapkan dengan rotary evaporator pada suhu $40^{\circ} \mathrm{C}$ sampai seluruh pelarut menguap dan diperoleh ekstrak kental.

\section{Partisi}

Partisi bertujuan untuk mengelompokkan metabolit yang terkandung dalam ekstrak kasar berdasarkan perbedaan polaritasnya. Sebelum melakukan partisi, ekstrak etanol kental dilarutkan dalam $100 \mathrm{~mL}$ campuran etanol-air (3:7), kemudian dievaporasi hingga semua etanol menguap dan diperoleh ekstrak dalam air. Selanjutnya dipartisi dengan n-heksana ( $5 \times 50 \mathrm{~mL})$. Ekstrak n-heksana dikumpulkan dan residu yang merupakan ekstrak air dipartisi kembali menggunakan etilasetat $(5 \times 50 \mathrm{~mL})$ kemudian ekstrak etilasetat dikumpulkan. Terakhir ekstrak air dipartisi dengan n-butanol $(5 \times 50 \mathrm{~mL})$. Ekstrak n-butanol dikumpulkan. Sehingga, pada tahap akhir diperoleh empat ekstrak, yaitu n-heksana, etilasetat, n-butanol, dan air. Keempat ekstrak dievaporasi sehingga diperoleh ekstrak kental. Masing-masing ekstrak selanjutnya diuji aktivitasnya sebagai antibakteri terhadap $S$. aureus.

\section{Pengujian aktivitas antibakteri}

Aktivitas antibakteri diuji dengan metode difusi agar menggunakan kertas cakram pada konsentrasi $15 \%$ dengan pengulangan sebanyak tiga kali. Kontrol negatif yang digunakan adalah pelarut dari ekstrak, sedangkan kontrol positif adalah Amoxicillin. Media menggunakan $20 \mathrm{~mL}$ media Nutrien Agar (NA) Mueller-Hinton yang dimasukkan ke dalam cawan petri steril kemudian ditutup dan didinginkan hingga memadat. Suspensi bakteri kemudian ditambahkan ke dalam nutrient agar dengan cara dioleskan pada permukaan media menggunakan kapas steril secara rapat dan didiamkan hingga agak mengering sekitar 5-8 menit sebelum ditempelkan cakram. Kertas cakram ditetesi ekstrak uji sebanyak $20 \mu \mathrm{L}$ menggunakan mikropipet, dan untuk kontrol negatif diteteskan pelarut $20 \mu \mathrm{L}$, kemudian didiamkan \pm 120 menit. Kertas cakram diletakkan diatas media bakteri dengan pinset dan inkubasi pada suhu $35-37^{\circ} \mathrm{C}$ selama 24 jam. Diameter hambat dari masing-masing ekstrak diukur setelah periode inkubasi menggunakan mistar. Senyawa yang paling aktif dalam menghambat pertumbuhan bakteri selanjutnya ditentukan konsentrasi hambat minimumnya.

\section{Penentuan konsentrasi hambat minimum}

Setelah diketahui fraksi yang paling aktif dalam menghambat bakteri maka ditentukan konsentrasi hambat minimum (KHM). KHM ditentukan untuk ekstrak yang aktif sebagai antibakteri dengan memvariasikan konsentrasinya, yaitu $0,5 \% ; 1,0 \%$; dan $1,5 \%$ (b/v). Prosedur penentuan KHM sama dengan pengujian aktivitas antibakteri sebelumnya namun hanya dilakukan variasi konsentrasi.

\section{Hasil dan Pembahasan}

Ekstraksi dilakukan menggunakan $2000 \mathrm{~g}$ daun trembesi dengan metode maserasi diperoleh ekstrak kental sebanyak $160 \mathrm{~g}$. Ekstrak etanol dimurnikan lebih lanjut melalui proses partisi, dimana partisi merupakan metode ekstraksi fase cair-cair dengan penambahan pelarut pengekstrak yang tidak saling melarutkan. Pada tahapan partisi diperoleh empat fraksi yaitu fraksi n-heksan yang berwarna hijau tua, fraksi etil-asetat yang berwarna hijau kecoklatan, fraksi n-butanol yang berwarna coklat tua, dan fraksi air yang berwarna coklat gelap. 
Pengujian aktivitas antibakteri terhadap $S$. aureus dari masing-masing fraksi hasil partisi dilakukan pada konsentrasi 15\% menggunakan media agar MH (Mueller Hinton). Sensitifitas bakteri terhadap sampel uji metode difusi agar dengan kertas cakram ditunjukkan dengan terbentuknya zona bening di sekitar kertas cakram yang menandakan daerah penghambatan pertumbuhan bakteri (Sinarsih dkk, 2016). Pemilihan amoxicillin sebagai kontrol positif terhadap $S$. aureus karena amoxicillin merupakan antibiotik turunan penisilin yang mempunyai spektrum kerja luas, dan mekanisme kerjanya menghambat sintesis dinding sel bakteri, khususnya untuk bakteri Gram positif (Fatimah dkk, 2015). Pengukuran zona bening pada hasil pengujian aktivitas antibakteri dari fraksi hasil partisi ekstrak etanol daun trembesi terhadap bakteri $S$. aureus memberikan hasil yang seperti terlihat pada Tabel 1.

Tabel 1. Diameter Zona Hambat Pertumbuhan Bakteri S. aureus dari Fraksi N-Heksan, Etil Asetat, N-Butanol, dan Air Ekstrak Etanol Daun Trembesi pada Konsentrasi 15\%

\begin{tabular}{clllll}
\hline \multirow{2}{*}{ Bakteri } & Fraksi & \multicolumn{3}{c}{$\begin{array}{c}\text { Pengukuran Zona Hambat } \\
\text { (mm) }\end{array}$} & \multirow{2}{*}{ Kesimpulan } \\
\cline { 2 - 5 } & $\mathbf{( 1 5 \% )}$ & $\mathbf{I}$ & II & III & \\
\hline \multirow{5}{*}{ S. aureus } & n-heksan & 0 & 0 & 0 & - \\
& etil asetat & 0 & 0 & 0 & - \\
& n-butanol & 19,5 & 19,5 & 18,5 & + \\
& air & 0 & 0 & 0 & - \\
& kontrol positif & 31,5 & 31 & 31,5 & + \\
& kontrol negatif & 0 & 0 & 0 & - \\
\hline
\end{tabular}

Kontrol negatif tidak menunjukkan adanya zona hambat pertumbuhan bakteri, yang berarti bahwa pelarut yang digunakan untuk partisi ekstrak dan pengencerannya tidak berpengaruh terhadap aktivitas antibakteri. Fraksi n-butanol menunjukkan aktivitas antibakteri dengan adanya zona hambat pertumbuhan bakteri rata-rata sebesar $19 \mathrm{~mm}$ namun fraksi lainnya tidak menunjukkan adanya zona hambat. Kriteria daya hambat pertumbuhan bakteri menurut Ardiansyah (2005) yaitu apabila ekstrak atau bahan uji memberikan diameter zona bening $<5 \mathrm{~mm}$ maka dikategorikan lemah, $5-10 \mathrm{~mm}$ dikategorikan sedang, >10 - $20 \mathrm{~mm}$ dikategorikan kuat, $>20 \mathrm{~mm}$ dikategorikan sangat kuat. Berdasarkan kategori tersebut, maka fraksi n-butanol ekstrak etanol daun trembesi pada konsentrasi $15 \%$ dapat dikategorikan memiliki daya hambat kuat terhadap S. aureus.

Suatu senyawa antibakteri dikatakan aktif apabila mampu memberikan daya hambat terhadap pertumbuhan suatu bakteri, dimana daya hambat suatu zat dikatakan efektif apabila besarnya daerah hambat (zona bening) sebanding dengan standar pengujian antibakteri (antibiotik). Apabila dibandingkan zona hambat yang dihasilkan antara fraksi $\mathrm{n}$-butanol terhadap kontrol positif maka kontrol positif memberikan aktivitas antibakteri yang lebih besar. Oleh karena itu, efektivitas fraksi n-butanol dapat dikatakan lebih kecil dibandingkan dengan antibiotik sebagai kontrol positif. Bila dibandingkan dengan fraksi lainnya, hanya fraksi n-butanol yang menunjukkan adanya aktivitas antibakteri terhadap $S$. aureus. Hasil tersebut kemungkinan disebabkan karena senyawa yang bersifat sebagai antibakteri sebagian besar terlarut dalam fraksi n-butanol, salah satunya golongan isoflavon (Suteja dkk., 2016). Pada penelitian yang dilakukan Suteja, dkk (2016), dari empat fraksi ekstrak etanol daun trembesi, hanya fraksi $n$ butanol yang menunjukkan aktivitas antibakteri terhadap $E$. coli dengan diameter hambat 6,3 $\mathrm{mm}$ pada konsentrasi $10 \%$.

Aktivitas antibakteri yang lebih besar pada $S$. aureus kemungkinan disebabkan karena perbedaan kompleksitas dinding sel bakteri. S. aureus sebagai bakteri Gram positif tersusun oleh struktur lapisan peptidoglikan yang lebih sederhana dibandingkan $E$. coli sebagai bakteri Gram negatif (Dewi, 2013). Hal ini menyebabkan senyawa-senyawa yang ada dalam fraksi nbutanol lebih mudah masuk ke dalam sel untuk merusak dinding sel bakteri sehingga fungsi dinding sel sebagai pemberi bentuk sel serta pelindung sel dari lisis terganggu yang mengakibatkan kematian bakteri (Dewi, 2013). Penentuan konsentrasi hambat minimum (KHM) fraksi n-butanol terhadap $S$. aureus dilakukan dengan uji pada berbagai konsentrasi yaitu $0,5 \%$, $1 \%$, dan 1,5\%. Hasil uji antibakteri untuk menentukan KHM disajikan pada Gambar 1. 


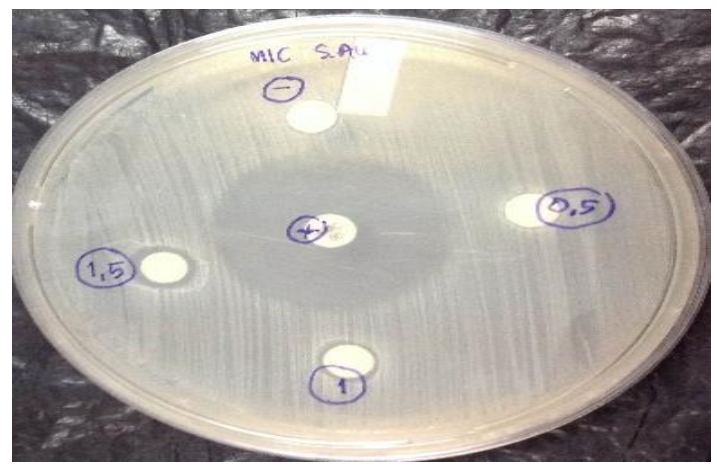

Gambar 1. Daya Hambat Fraksi N-Butanol Pada Berbagai Konsentrasi Pada S. aureus

Besarnya diameter zona hambat $\mathrm{KHM}$ dari fraksi n-butanol terhadap $S$. aureus ditunjukkan pada Tabel 2.

Tabel 2. Diameter Zona Hambat Pertumbuhan Bakteri Pada Uji KHM S. aureus dari Berbagai Konsentrasi Fraksi N-Butanol

\begin{tabular}{lccccc}
\hline \multirow{2}{*}{ Bakteri } & $\begin{array}{c}\text { Konsentrasi N- } \\
\text { butanol }\end{array}$ & \multicolumn{3}{c}{ Pengukuran Zona Hambat } & Kesimpulan \\
\cline { 2 - 5 }$(\mathbf{m m})$ & I & II & III & \\
\hline \multirow{3}{*}{ S. aureus } & 0,5 & 0 & 0 & 0 & - \\
& 1 & 7 & 8 & 7 & + \\
& 1,5 & 9 & 9 & 9,5 & + \\
& kontrol negatif & 0 & 0 & 0 & - \\
kontrol positif & 33 & 31 & 32 & + \\
\hline
\end{tabular}

Hasil pengujian menunjukkan bahwa semakin tinggi konsentrasi fraksi n-butanol ekstrak etanol daun trembesi maka diameter zona hambat semakin besar. Hasil tersebut sesuai dengan pernyataan Rhoades dan Roller (2000) serta Pelczar dan Chan (1988), bahwa pada umumnya besar daya hambat (diameter zona hambat) cenderung meningkat sebanding dengan meningkatnya konsentrasi ekstrak. Pada konsentrasi 0,5\%, fraksi n-butanol tidak menunjukkan adanya efek penghambatan yang ditandai dengan tidak adanya zona bening. Oleh karena itu maka dapat dikatakan bahwa KHM fraksi n-butanol dari ekstrak etanol daun trembesi pada penelitian ini sebesar $1 \%$.

\section{Simpulan dan Saran}

Berdasarkan hasil penelitian, dapat disimpulkan bahwa fraksi hasil partisi ekstrak etanol daun trembesi pada konsentrasi 15\% yang dapat menghambat pertumbuhan bakteri $S$. aureus adalah fraksi dari n-butanol. Nilai konsentrasi hambat minimum (KHM) dari fraksi yang aktif sebagai antibakteri yaitu n-butanol sebesar 1\%. Penggunaan daun trembesi sebagai antibakteri akan dapat lebih dikembangkan apabila dilakukan penelitian lebih lanjut untuk uji farmakologis aktivitas antibakteri pada hewan coba secara in-vivo, serta uji toksisitas.

\section{Daftar Pustaka}

Ardiansyah. 2005. Daun Beluntas sebagai Bahan Antibakteri dan Antioksidan. Tersedia pada [http://www.berita_iptek.com/cetak_beritahp?kat=berita \&id=33]. diakses pada tanggal 18 Juli 2015.

Dewi, A.K. 2013. Isolasi, Identifikasi dan Uji Sensitivitas Staphylococcus aureus terhadap Amoxicillin dari Sampel Susu Kambing Peranakan Ettawa (PE) Penderita Mastitis di Wilayah Girimulyo, Kulonprogo, Yogyakarta. Jurnal Sain Veteran. 31(2): 130138Jawetz, E., Melnick, J.L., Adelberg, E.A. 1995. Mikrobiologi Kedokteran. Penerbit Buku Kedokteran EGC. Jakarta.

Fatimah, I., Kisrini, Wibawa, D.A.A. 2015. Uji Kepekaan Bakteri Klebsiella sp. Hasil Isolasi Ulkus Diabetes Pasien Rawat Inap Di RSUD Dr. Moewardi terhadap Antibiotik Meropenem, Gentamisin, Seftriakson, dan Siprofloksasin pada Bulan Februari-Maret Tahun 2014. Jurnal Farmasi Indonesia.12(1): 33-40 
Kumala, S., E. Agustina, dan P. Wahyudi. 2007. Uji Aktivitas Antimikroba Metabolit Sekunder Kapang Endofit Tanaman Trengguli. Jurnal Bahan alam Indonesia. 6(2): 46-48.

Parubak, A. S. 2013. Senyawa Flavonoid Yang Bersifat Antibakteri dari Akway (Drimys beccariana Gibbs), Chem. Prog. 6 (1): 34-37. 141-148

Pelczar, M.J., dan Chan, E.C.S. 2010. Dasar-Dasar Mikrobiologi. Jakarta: UI-Press

Rhoades, J., Roller, S. 2000. Antimicrobial Actions of Degraded and Native Chitosan against Spoilage Organisms in Laboratory Media and Foods. Applied And Environmental Microbiology. 66(1): 80-86

Sinarsih, N.K., Rita, W.S., Puspawati, N.M., 2016. Uji Efektivitas Ekstrak daun Trembesi (Samanea saman (Jacq.)) sebagai Antibakteri Escherichia coli dan Staphylococcus aureus, Cakra Kimia. 4(2): 129-136

Suteja, IKP., Rita, WS., Gunawan. IWG. 2016. Identifikasi dan Uji Aktivitas Senyawa Flavonoid Dari Ekstrak Daun Trembesi. Jurnal Kimia. 10(1). 